\title{
Impact of conversion on outcome in laparoscopic colorectal cancer surgery
}

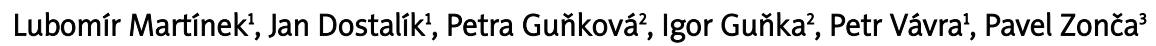 \\ ${ }^{1}$ Faculty of Medicine, University of Ostrava, Czech Republic \\ ${ }^{2}$ Clinic of Surgery, University Hospital Ostrava, Czech Republic \\ 3Zentrum für Viszeral und Minimal Invasive Chirurgie, Wesseling, Köln am Rhein, Germany
}

Videosurgery and Other Miniinvasive Techniques 2012; 7 (2): 74-81 DOI: 10.5114/wiitm.2011.25799

\begin{abstract}
Introduction: Long-term results after laparoscopic surgery with conversion to open surgery for colorectal cancer are seldom published.

Aim: The study analysed the impact of conversion of laparoscopic surgery to open resection for colorectal cancer on short- and long-term results.

Material and methods: The prospectively collected data of 469 patients with colorectal cancer in the period from 1 January 2001 to 31 December 2006 were analysed. Short-and long-term results were compared.

Results: The relative frequency of conversion was $7 \%$. The subgroups were statistically similar regarding age, gender, body mass index (BMI), localization of tumour, T stage, and TNM stage. We observed a lower frequency of previous surgery $(p=0.018)$ in the group of patients with conversions to open surgery as well as statistically significantly higher frequency of patients with American Society of Anesthesiologists (ASA) score II ( $p=0.039)$. There was no statistical difference in morbidity, mortality, or the length of hospital stay between both the groups of patients. The operating time was significantly higher in the group of patients with conversion $(p=0.00001)$. There was a significantly higher blood loss in the patient groups with conversion to open surgery and in the group with primarily open surgery ( $p=0.00023)$. There was no difference in the overall survival $(p=0.712)$, disease-free survival $(p=0.072)$ or in the local $(p=0.432)$ or distant $(p=0.957)$ recurrence.

Conclusions: No negative impact on short- or long-term results of conversion to open surgery was verified in patients with colorectal surgery.
\end{abstract}

Key words: laparoscopic resection, conversion, colorectal surgery, colorectal cancer, survival.

\section{Introduction}

Laparoscopic surgery for colorectal cancer is a standardized procedure. The results of prospectively randomized trials and meta-analysis have shown a better postoperative course [1-5]. The oncological safety was verified as well [6-8]. The reliability of those results in rectal cancer resection is limited because of the lack of high quality trials [2, 9-11]. The laparoscopic approach is a standard [5, 12]; however, the complicated intraoperative findings or intraoperative complications can provide a reason for conversion to open surgery. Conversion to open surgery could not only result in loss of the advantage of laparoscopy $[13,14]$, but also could lead to potentially worse survival according to some authors $[15,16]$. 


\section{Aim}

The aim of our trial is to evaluate the impact of conversion of laparoscopic resection for colorectal cancer on short-term and long-term results.

\section{Material and methods}

The data of 469 patients with histologically verified colorectal cancer were included in the prospective study and analysed in the period from 1 January 2001 to 31 December 2006. The follow-up was performed until 31 December 2008. The minimal followup of 24 months was achieved. Patients with perforation or obstruction, patients with cancer recurrence or multiple malignancies or patients with incomplete data in follow-up were excluded. The decision of a well-informed patient was respected in the choice of open or laparoscopic surgery. The surgery was performed by a team of three well-experienced surgeons in open as well as laparoscopic surgery. The following data were collected: patients' data (age, gender, body mass index - BMI, ASA score, previous surgery), tumour data (localization, staging according to the International Union against Cancer/American Joint Committee on Cancer - UICC/AJCC), surgery (operating time, blood loss, cause of conversion, number of lymph nodes), postoperative course (postoperative complications, morbidity, mortality, length of hospital stay), long-term results (recurrence, survival, disease-free interval). Manually-assisted laparoscopic procedures were integrated into the laparoscopic group.

The follow-up protocol for the first 3 years generally included physical examination and tumour marker tests (carcinoembryonic antigen, Ca 19-9) every 3 months, colonoscopy and abdominal ultrasound every 6 months, and computed tomography (CT) scan (abdomen, pelvis) and chest X-ray (preferably $\mathrm{CT}$ scan of the chest) every 12 months. During years 4 and 5, physical examination and tumour marker tests are usually recommended every 6 months, CT scans (abdomen, pelvis), colonoscopy and chest X-ray (preferably CT scan of the chest) every 12 months. After five years, physical examination and tumour marker tests are planned every year and colonoscopy should be done every 2 years. Because the patient's risk of recurrence was variable, these guidelines were modified depending on the individual situation. Magnetic resonance imaging $(\mathrm{MRI})$, positron emission tomography - computed tomography (PET/CT) or virtual colonoscopy was used according to the situation.

Conversion was defined as an unplanned laparotomy or wound enlargement above the necessity for specimen removal. Morbidity was represented by complications which required medicamentous or operative treatment. Mortality involved deaths up to 30 days after the surgery. Local recurrence was defined as a histologically verified anastomosis site recurrence. In the case of rectal cancer, a local recurrence is considered to be a recurrence in the small pelvis or perineum. Tumours up to $16 \mathrm{~cm}$ from the anal verge by rigid rectoscopy were considered as rectal tumours.

The trial data were analysed by using the Statistic Software (Version 9, StatSoft ${ }^{\circledR}$, US). The analysis of variance test (ANOVA) for analysis of continuous variables and the $\chi^{2}$ test for categorical variables were performed. Kaplan-Meier curves of survival were compared with log-rank tests. Patients who died within the first 30 days after the surgery were not involved in the survival analysis. Value of $p$ below 0.05 was defined as statistically significant.

\section{Results}

The data of 469 patients with elective resection of histologically verified colorectal cancer in the period from 1 January 2001 to 31 December 2006 were included in the analysis (Figure 1).

Laparoscopy was performed in 243 patients. Conversion to open surgery was necessary in 17 patients (7\%). Primary open resection was performed in 226 patients. The patients who died within 30 days after the surgery were included in the analysis of shortterm results, but they were not included in the longterm results. The demographic and clinical parameters of the subgroups are shown in Table I.

No statistically significant difference in age, gender, BMI, localization of tumour (colon vs. rectum), T stage or TNM stage (UICC/AJCC) between the groups was found. A lower frequency of previous abdominal surgery $(p=0.018)$ and a higher frequency of patients with ASA score $\|(p=0.039)$ in the group of patients with conversion was found in comparison with the subgroup with laparoscopy and primary open surgery.

The procedures performed in each group are shown in Table II. Except for bypass surgery ( $p=0.00005)$, 


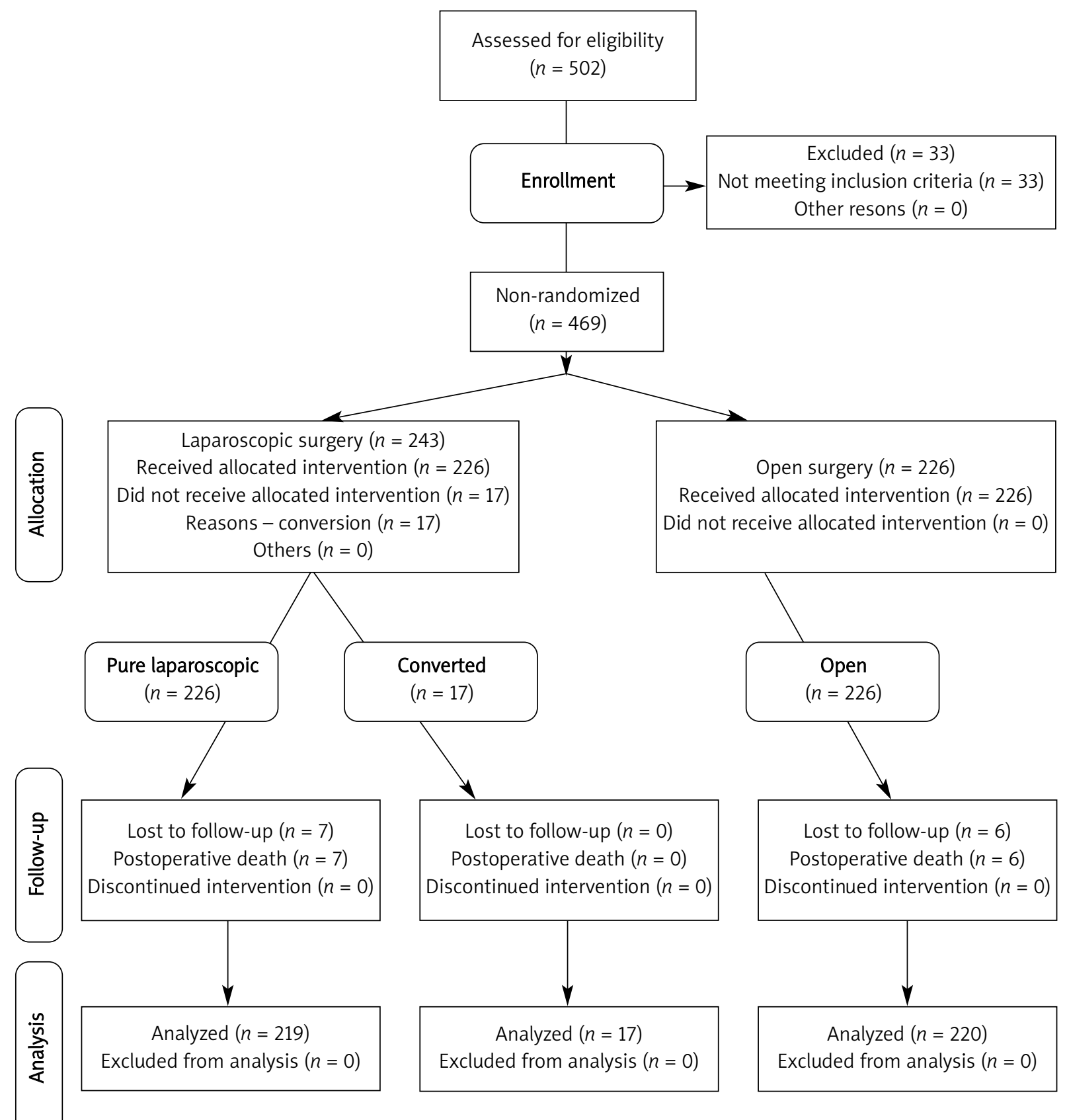

Figure 1. Study flow diagram

there were no significant differences as for the type of surgical procedure. Reasons for conversion are shown in Table III. The most frequent causes of conversion were multiple adhesions and the inability to correctly identify anatomy. Ten operations (6.3\%) in the group of colon cancer and 7 operations (8.2\%) of patients with rectal cancer underwent conversion. There is no statis- tical difference in the frequency of conversion between the groups $(p=0.578)$.

The operation data are summarized in Table IV. There was no statistical difference in the hospital stay, morbidity, or mortality between the compared groups. Operating time was significantly higher in the group of patients with conversion $(p<0.001)$. Blood loss was 
Table I. Demographic and clinical parameters of subgroups

\begin{tabular}{|c|c|c|c|c|}
\hline Parameter & $\begin{array}{l}\text { Laparoscopy } \\
(n=226)\end{array}$ & $\begin{array}{l}\text { Conversion } \\
(n=17)\end{array}$ & $\begin{array}{l}\text { Open surgery } \\
(n=226)\end{array}$ & $\begin{array}{l}\text { Value } \\
\text { of } p\end{array}$ \\
\hline Age [years] & $64.5 \pm 10.6$ & $62.8 \pm 8.2$ & $65.8 \pm 10.8$ & 0.314 \\
\hline $\begin{array}{l}\text { Gender } \\
\text { (men : women) }\end{array}$ & $146: 80(65 \%: 35 \%)$ & $13: 4(76 \%: 24 \%)$ & $\begin{array}{c}146: 80 \\
(65 \%: 35 \%)\end{array}$ & 0.602 \\
\hline BMI $\left[\mathrm{kg} / \mathrm{m}^{2}\right]$ & $26.7 \pm 4.0$ & $28.4 \pm 5.4$ & $27.3 \pm 4.6$ & 0.142 \\
\hline $\begin{array}{l}\text { ASA classification } \\
(I: \|:|I| \text { IV) }\end{array}$ & $\begin{array}{c}16: 107: 93: 10 \\
(7 \%: 47 \%: 41 \%: 4 \%)\end{array}$ & $\begin{array}{c}1: 13: 2: 1 \\
(6 \%: 76 \%: 12 \%: 6 \%)\end{array}$ & $\begin{array}{c}25: 102: 96: 3 \\
(11 \%: 45 \%: 42 \%: 1 \%)\end{array}$ & 0.039 \\
\hline Previous abdominal surgery & $84(37 \%)$ & $3(18 \%)$ & $105(46 \%)$ & 0.018 \\
\hline $\begin{array}{l}\text { Localization of tumour } \\
\text { (colon: rectum) }\end{array}$ & $\begin{array}{c}148: 78 \\
(65 \%: 35 \%)\end{array}$ & $\begin{array}{c}10: 7 \\
(56 \%: 44 \%)\end{array}$ & $\begin{array}{c}139: 87 \\
(62 \%: 38 \%)\end{array}$ & 0.629 \\
\hline T stage (T1: T2: T3: T4) & $\begin{array}{c}22: 20: 130: 54 \\
(10 \%: 9 \%: 58 \%: 23 \%)\end{array}$ & $\begin{array}{c}1: 1: 8: 7 \\
(6 \%: 6 \%: 47 \%: 41 \%)\end{array}$ & $\begin{array}{c}9: 30: 131: 56 \\
(4 \%: 13 \%: 58 \%: 25 \%)\end{array}$ & 0.118 \\
\hline $\begin{array}{l}\text { TNM stage } \\
(I: \|: I I I: \text { IV) }\end{array}$ & $\begin{array}{c}33: 71: 86: 36 \\
(15 \%: 31 \%: 38 \%: 16 \%)\end{array}$ & $\begin{array}{c}1: 2: 11: 3 \\
(6 \%: 12 \%: 65 \%: 18 \%)\end{array}$ & $\begin{array}{c}32: 73: 77: 44 \\
(14 \%: 32 \%: 34 \%: 19 \%)\end{array}$ & 0.244 \\
\hline
\end{tabular}

Table II. Procedures performed

\begin{tabular}{|lcccc|}
\hline Procedure & $\begin{array}{c}\text { Laparoscopy } \\
(n=226)\end{array}$ & $\begin{array}{c}\text { Conversion } \\
(n=17)\end{array}$ & $\begin{array}{c}\text { Open surgery } \\
(n=226)\end{array}$ & $\begin{array}{c}\text { Value } \\
\text { of } p\end{array}$ \\
\hline Right hemicolectomy & $54(24 \%)$ & $3(18 \%)$ & $45(20 \%)$ & 0.541 \\
\hline Transverse colectomy & $2(1 \%)$ & $0(0 \%)$ & $5(2 \%)$ & 0.444 \\
\hline Left hemicolectomy & $18(8 \%)$ & $2(12 \%)$ & $41(7 \%)$ & 0.765 \\
\hline Sigmoid colectomy & $38(17 \%)$ & $3(18 \%)$ & $38(17 \%)$ & 0.933 \\
\hline Low anterior resection & $52(23 \%)$ & $5(29 \%)$ & $23(10 \%)$ & 0.165 \\
\hline Abdominoperineal resection & $23(10 \%)$ & $1(6 \%)$ & $24(11 \%)$ & 0.846 \\
\hline Intestinal bypass & $2(1 \%)$ & $1(6 \%)$ & $27(12 \%)$ & 0.00005 \\
\hline Stoma creation & $32(14 \%)$ & $1(6 \%)$ & $5(2 \%)$ & 0.535 \\
\hline Total colectomy & $5(2 \%)$ & $1(6 \%)$ & $2(1 \%)$ & 0.618 \\
\hline Hartmann procedure & $0(0 \%)$ & $0(0 \%)$ & 0.840 \\
\hline
\end{tabular}

significantly higher in the conversion group compared to the laparoscopically operated group $(p<0.001)$. A lower number of harvested lymph nodes $(p=0.017)$ and a higher blood loss $(p<0.001)$ were found in the group of primary open surgery compared to the laparoscopic operations. There was no difference in resection margins in the analysed groups.

The analysis of long-term results (overall survival, disease-free survival) is shown in Figures 2 and 3.
Our trial identified a tendency toward a longer survival period in the laparoscopic group; however, no statistically significant difference was confirmed (overall survival: $p=0.712$, disease-free survival: $p=0.072$ ). The incidence of recurrence is shown in Table V.

The median follow-up in the group with laparoscopy was 58 months (25-91 months), 66 months (25-92 months) in the group with conversion and 
Table III. Intraoperative reasons for conversion

\begin{tabular}{|lc|}
\hline Reason & Number \\
\hline $\begin{array}{l}\text { Anatomical conditions (adhesions, low } \\
\text { visualization, narrow small pelvis) }\end{array}$ & 6 \\
\hline $\begin{array}{l}\text { Intraoperative complications (bleeding, } \\
\text { bowel injury, stapler malfunction) }\end{array}$ & 5 \\
\hline Tumour (size, invasion) & 3 \\
\hline $\begin{array}{l}\text { Others (failure of equipment, acute } \\
\text { myocardial infarction, tumour's exact location) }\end{array}$ & 3 \\
\hline Total & 17 (7\%) \\
\hline
\end{tabular}

75 months (25-96 months) in the group with open surgery.

\section{Discussion}

Despite the technical improvements in the last decades, laparoscopic resection of colorectal cancer is technically demanding surgery with an unavoidable risk of conversion. The conversion itself causes the loss of the advantage of minimally invasive surgery and the negative influence on oncological results as has been discussed $[13,15-18]$. The aim of this trial is to investigate this impact. The frequency

Table IV. Surgery data

\begin{tabular}{|lcccc|}
\hline Parameter & $\begin{array}{c}\text { Laparoscopy } \\
(n=226)\end{array}$ & $\begin{array}{c}\text { Conversion } \\
(n=17)\end{array}$ & $\begin{array}{c}\text { Open surgery } \\
(n=226)\end{array}$ & $\begin{array}{c}\text { Value } \\
\text { of } p\end{array}$ \\
\hline Operating time [min] & $152 \pm 47$ & $224 \pm 76$ & $155 \pm 58$ & 0.000001 \\
\hline No. of lymph nodes sampled & $13 \pm 8$ & $13 \pm 7$ & $11 \pm 7$ & $1(0.4 \%)$ \\
\hline Positive resection margin & $1(0.4 \%)$ & $0(0.0 \%)$ & $305 \pm 434$ & 0.017 \\
\hline Blood loss [ml] & $177 \pm 293$ & $415 \pm 425$ & $12.0 \pm 6.3$ & 0.00023 \\
\hline Hospital stay [days] & $11.3 \pm 5.8$ & $12.5 \pm 4.6$ & $72(31.9 \%)$ & 0.390 \\
\hline Morbidity & $65(28.8 \%)$ & $6(35.3 \%)$ & $6(2.7 \%)$ & 0.703 \\
\hline Mortality & $7(3.1 \%)$ & $0(0.0 \%)$ & 0.746 \\
\hline
\end{tabular}

Table V. Incidence of recurrence

\begin{tabular}{|lcccc|}
\hline & $\begin{array}{c}\text { Laparoscopy } \\
(n=226)\end{array}$ & $\begin{array}{c}\text { Conversion } \\
(n=17)\end{array}$ & $\begin{array}{c}\text { Open surgery } \\
(n=226)\end{array}$ & $\begin{array}{c}\text { Value } \\
\text { of } p\end{array}$ \\
\hline Local recurrence & $7(3.8 \%)$ & $1(7.1 \%)$ & $12(6.7 \%)$ & 0.432 \\
\hline Distant recurrence & $30(17.3 \%)$ & $2(14.3 \%)$ & $30(16.9 \%)$ & 0.957 \\
\hline
\end{tabular}

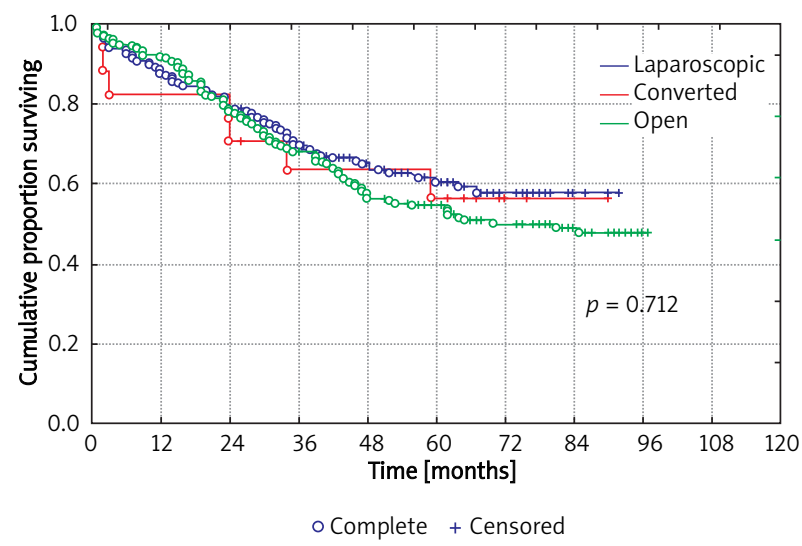

Figure 2. Overall survival

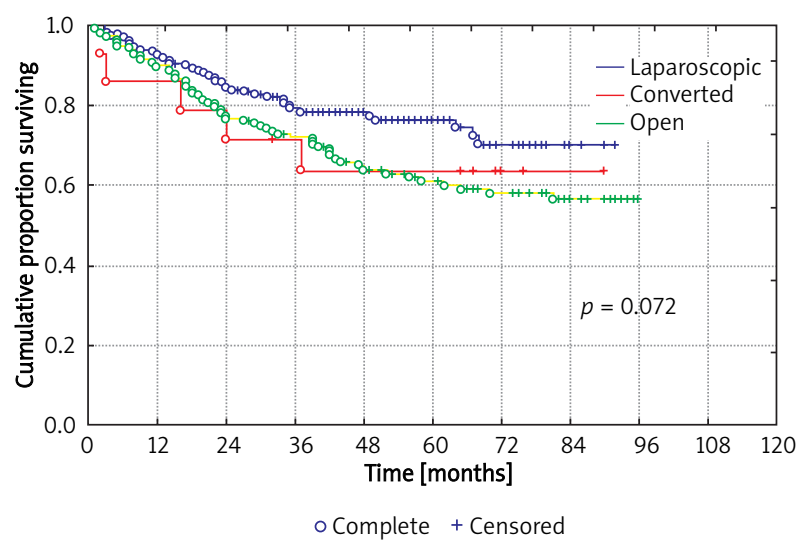

Figure 3. Disease-free survival 
of conversion in laparoscopic colorectal surgery is estimated at 2-41\% according to the studies; mostly the studies report a frequency of $7-25 \%[14,18]$. Many factors influence the conversion rate patients' data, type of surgery, the surgeon's experience - but the definition of "conversion" also plays a role. The conversion rate is $7 \%$ in our study $(17 / 469$ patients). The most frequent cause of conversion is the disadvantageous anatomical conditions and intraoperative complications. The lower conversion rate in our trial is due to the standardization of laparoscopy and the surgeon's extensive experience with more than 1000 laparoscopic colorectal procedures in our institution.

The compared groups of patients (with laparoscopic surgery, conversion, and primary open surgery) showed no statistical difference despite no randomization in every subgroup regarding age, gender, BMI, T stage, TNM stage, and the ratio of colon and rectal cancer.

The ASA-II stage connected with a better outcome was significantly higher $(p=0.039)$ in the group with conversion (compared with the laparoscopic and open groups). Surprisingly, the group with conversion had a significantly lower frequency of previous intraabdominal surgery $(p=0.018)$. In contrast to the trial performed by Tekkis et al. [19] and Chan et al. [13], we found no significantly higher incidence of T3 and T4 tumour stages ( $p=0.118$ ) in the subgroup of patients with conversion. We found no significantly higher conversion rate in stage IV $(p=0.244)$, as it was referred in the trial by Molloo et al. [15].

The operating time in the subgroup with secondary conversion was statistically higher $(p<0.001)$ than it was stated in some other studies [9, 11, 20, 21]. The early decision of conversion could significantly shorten the surgery time according to some of the studies [13, 22]. The intraoperative blood loss was statistically significantly higher in the group with conversion as well as in the group with primary open surgery $(p<0.001)$. However, the real significance of those differences in millilitres is clinically disputable.

The group with conversion had higher morbidity, but this difference was not statistically significant $(p=0.703)$. Similar results regarding morbidity have been presented in more studies including the multicentre randomized CLASICC trial [23]. Within the period of 30 days after the surgery no case of death appeared in the group of patients with conversion. Most of the trials published up to now including the meta-analysis of 28 non-randomized trials by Gervaz et al. [14] have shown longer hospital stay in the group of patients with conversion as a result of the higher morbidity in this group. On the other hand, our trial has shown no significantly longer inpatient stay or higher morbidity in the group with conversion. It is probably due to the similar distribution of postoperative complications in all the compared groups of patients.

Most of the trials conducted up to now have focused on the impact of conversion on the shortterm results in laparoscopic colorectal surgery. The impact of conversion on the long-term results in colorectal cancer has hardly ever been evaluated. Moloo et al. [15] published results with significantly lower survival in patients with conversion after 2 years; a similar tendency was observed in 5 years, but both of them had no statistical significance. This evaluation was performed in the group of patients with stage I according to UICC/AJCC, which is a limiting factor. Chan et al. [13] compared the long-term results of laparoscopic resection and surgery with conversion in colorectal surgery. These authors found a shorter disease-free interval and higher probability of local recurrence in the group with conversion. Despite these unfavourable results, the overall survival was similar in both the groups. Similar results were published by Ptok et al. in a trial with rectal cancer [21]. The highest incidence of local recurrence and a shorter disease-free interval were found in the group of patients with conversion, but the differences had no statistical significance. Ströhlein et al. [16] reported higher incidence of metachronous metastases and local recurrence in the group with conversion for rectal cancer. In contrast, Laurent et al. [24] found identical incidence in local and distant recurrences after conversion and surgery without conversion in patients with rectal cancer. The authors found comparable 5-year survival including diseasefree survival in both the groups. Franko et al. [20] described no difference regarding 2-, 3-, and 5-year survival between the groups with and without conversion in their trial with patients with colon cancer.

In compliance with the above studies, our trial did not show any poorer oncological results regarding survival, disease-free survival, and the incidence of local and distant recurrences in the group with conversion. 
It needs to be said that the statistical evaluation of our trial is limited on account of the relatively low conversion rate (type II error). It would be necessary to have more than 800 patients to verify the 12-month overall survival difference between the laparoscopically resected group and the converted group with the conversion rate at $20 \%$. The clinical experience shows that the incidence of conversion is lower. If a difference in survival exists, then it is considerably lower. It would involve the analysis of such a number of patients which is technically hard to achieve. The parallel development in adjuvant therapy in colorectal cancer has a significant impact on survival and influences the long-term results. The non-randomized single-centre design of our trial could involve potential bias, despite the statistical analysis of basic parameters which have been similar as described. Moreover, the results from one specialized centre could be generalized with limitations. Despite that, our trial results as well as the trials published up to now have shown that the negative impact of the conversion on the outcome for laparoscopic colorectal resection should be considered.

Higher risks of postoperative complications or worse long-term survival for patients have not been confirmed in our trial. The results obtained in our trial were accomplished due to the standardization of operation technique achieved by surgeons with extensive experience acquired over a long period and a lower conversion rate. Reliable long-term results from trials with a higher number of patients and results of multi-centre randomized trials dealing with the topic have never been published.

\section{Conclusions}

In our trial we have not confirmed a negative impact of conversion of laparoscopic colorectal resection on short- or long-term results. The standardization of operation technique, precise indications for laparoscopic surgery with low conversion rate, and continuous verification of achieved results are presumptions of good results. Further trials with more reliable proof for verification of oncological certainty of laparoscopically started procedures and secondary converted operations in the field of colorectal surgery are necessary for the safe indication of laparoscopic surgery in patients with high risk of conversion.

\section{References}

1. Abraham NS, Young JM, Solomon MJ. Meta-analysis of shortterm outcomes after laparoscopic resection for colorectal cancer. Br J Surg 2004; 91: 1111-24.

2. Aziz O, Constantinides V, Tekkis PP, et al. Laparoscopic versus open surgery for rectal cancer: a meta-analysis. Ann Surg Oncol 2006; 13: 413-24.

3. Gao F, Cao YF, Chen LS. Meta-analysis of short term outcomes after laparoscopic resection for rectal cancer. Int J Colorectal Dis 2006; 21: 652-6.

4. Schwenk W, Haase O, Neudecker JJ, et al. Short term benefits for laparoscopic colorectal resection. Cochrane Database Syst Rev 2005; 3: CD003145.

5. Piatkowski J, Jackowski M. Laparoscopic colon resections - own experience report. Videsurgery and Other Miniinvasive Techniques 2009; 4: 135-7.

6. Bonjer HJ, Hop WCJ, Nelson H, et al. Laparoscopically assisted vs open colectomy for colon cancer. Arch Surg 2007; 142: 298-303.

7. Fleshman J, Sargent DJ, Green E, et al. Laparoscopic colectomy for cancer is not inferior to open surgery based on 5-year data from the COST study group trial. Ann Surg 2007; 246: 655-62.

8. Jackson TD, Kaplan GG, Arena G, et al. Laparoscopic versus open resection for colorectal cancer: a metaanalysis of oncologic outcomes. J Am Coll Surg 2007; 204: 439-46.

9. Anderson C, Uman G, Pigazzi A. Oncologic outcomes of laparoscopic surgery for rectal cancer: a systematic review and metaanalysis of the literature. Eur J Surg Oncol 2008; 34: 1135-42.

10. Jayne DG, Guillou PJ, Thorpe $H$, et al. Randomised trial of Laparoscopic-assisted resection of colorectal carcinoma: 3-year results of the UK MRC CLASICC trial group. J Clin Oncol 2007; 25: 3061-8.

11. Lujan J, Valero G, Hernandez Q, et al. Randomized clinical trial comparing laparoscopic and open surgery in patients with rectal cancer. Br J Surg 2009; 96: 982-9.

12. Duda M, Gryga A, Czudek S, Skalický P. Twenty years of minimally invasive surgery in the Czech Republic. Videsurgery and Other Miniinvasive Techniques 2011; 6: 42-7.

13. Chan ACY, Poon JTC, Fan JKM, et al. Impact of conversion on the long-term outcome in laparoscopic resection of colorectal cancer. Surg Endosc 2008; 22: 2625-30.

14. Gervaz P, Pikarsky A, Utech M, et al. Converted laparoscopic colorectal surgery. Surg Endosc 2001; 15: 827-32.

15. Moloo H, Mamazza J, Poulin EC, et al. Laparoscopic resection for colorectal cancer. Does conversion affect survival? Surg Endosc 2004; 18: 738-5.

16. Ströhlein MA, Grützner KU, Jauch KW, et al. Comarison of laparoscopic vs. open access surgery in patients with rectal cancer: a prospective analysis. Dis Colon Rectum 2008; 51: 385-91.

17. Belizon A, Sardinja CT, Sher ME. Converted laparoscopic colectomy. What are the consequences? Surg Endosc 2006; 20: 947-51.

18. Marusch F, Gastinger I, Schneider C, et al. Importance of conversion for results obtained with laparoscopic colorectal surgery. Dis Colon Rectum 2001; 44: 207-16.

19. Tekkis PP, Senagore AJ, Delaney CP. Conversion rates in laparoscopic colorectal surgery. Surg Endosc 2005; 19: 47-54 
20. Franko J, Fassler SA, Rezvani M, et al. Conversion of laparoscopic colon resection does not affect survival in colon cancer. Surg Endosc 2008; 22: 2631-4.

21. Ptok H, Steinert R, Meyer F, et al. Long-term oncological results after laparoscopic, converted and primary open procedures for rectal carcinoma. Results of multicenter observational study. Chirurg 2006; 77: 709-17.

22. Agachan F, Joo JS, Sher M, et al. Laparoscopic colorectal surgery. Do we get farter? Surg Endosc 1997; 11: 331-5.

23. Guillou PJ, Quirke P, Thorpe H, et al. Short-term endpoints of conventional versus laparoscopic-assisted surgery in patiens with colorectal cancer (MRC CLASICC trial): multicentre, randomised controlled trial. Lancet 2005; 365: 1718-26.

24. Laurent C, Leblanc F, Wütrich P, et al. Laparoscopic versus open surgery for rectal cancer. Long term oncologival results. Ann Surg 2009; 250: 54-61. 